Seen in the context of the cloning of a protein termed PHAS-I earlier this year ${ }^{7}$, the potential significance of the two 'new' proteins became clear. PHAS-I was first identified as a protein whose phosphorylation was rapidly enhanced by insulin in rat fat cells ${ }^{8}$, and 4E-BP1 is its human counterpart. Pause et al. ${ }^{2}$ and Lin et al. ${ }^{4}$ went on to demonstrate that insulin treatment of fat cells disrupts the interaction of 4E-BP1 with eIF-4E (presumably as a consequence of the phosphorylation of 4E-BP1). This interaction seems to inhibit translation, so these observations provide evidence of a mechanism by which insulin (and other agents, such as certain growth factors, which also increase the phosphorylation of this or a closely related protein $^{9}$ ) could stimulate translation. The protein seems to be present in all insulinsensitive tissues ${ }^{4,7,10,11}$.

It is not yet clear how the interaction with 4E-BP1 blocks translation, but it probably impairs the binding of eIF-4E to eIF-4A or eIF-4 $\gamma$ (or both). The working hypothesis is therefore as follows. Enhanced phosphorylation of 4E-BP1 leads to its dissociation from elF-4E, allowing this protein to interact with eIF- $4 \mathrm{~A} / 4 \gamma$ to form a functional complex. This would particularly facilitate the translation of mRNAs whose 5'UTRs contain significant secondary structure and are therefore especially dependent on elF-4A function. An example may be the mRNA for ornithine decarboxylase: its $5^{\prime}$ UTR is highly structured and its translation is increased by insulin ${ }^{12}$ or by overexpression of eIF-4E (ref. 13).

Which protein kinase (or kinases) mediates the increase in 4E-BP1 phosphorylation in response to insulin? In their paper Haystead $\mathrm{et} \mathrm{al}^{3}$ show that MAP kinase phosphorylates the rat homologue of $4 \mathrm{E}$ BP1 (PHAS-I) at a single serine residue (Ser 64), which is also phosphorylated in response to insulin in adipocytes. MAP kinase is activated by insulin and growth factors in many types of cell. Indeed, Lin et al. show that the two isoforms of MAP kinase are the major PHAS-I kinases in epidermal growth factor-stimulated 3T3L1 adipocytes ${ }^{4}$. Furthermore, phosphorylation of PHAS-I in vitro by MAP kinase blocks its ability to bind to eIF-4E $\mathrm{E}^{4}$. But the protein contains phosphothreonine as well as phosphoserine, so it can also be phosphorylated by at least one other protein kinase. It is not yet clear whether $4 \mathrm{E}-\mathrm{BP} 2$ is also phosphorylated or, if it is, under what conditions this might be brought about.

The picture can be broadened to include other notable developments. It has been known for many years that the ribosomal protein $S 6$, in the $40 S$ subunit, undergoes increased phosphorylation in response to many agents that stimulate translation, through the activation of a specific protein kinase $\left(\mathrm{p} 70^{\mathrm{s} 6 \mathrm{k}}\right)$. Despite recent detailed studies, the mechanism of activation of $\mathrm{p} 70^{\mathrm{s} 6 \mathrm{k}}$ remains obscure ${ }^{14}$. The function of S6 phosphorylation had also been unclear, but work published in May ${ }^{15}$ has shed fresh light on this question. Rapamycin is an immunosuppressant that blocks activation of $\mathrm{p} 70^{\mathrm{s} 6 \mathrm{k}}$ and S6 phosphorylation, and Jefferies et al ${ }^{15}$ showed that it also blocks the recruitment of mRNAs containing polypyrimidine tracts into polysomes; this indicates that phosphorylation of S6 is central to this process.

Another potential regulatory mechanism which has recently been revealed involves the initiation factor eIF-2B, a guanine-nucleotide-exchange factor which maintains the initiator transferRNA-binding factor, elF-2, in its active GTP-bound state, thus ensuring the supply of initiator methionyl-tRNA to the ribosome. The exchange activity of this factor is acutely stimulated by insulin and growth factors, and has been shown to be phosphorylated and apparently inactivated by glycogen-synthase kinase-3 (GSK-3) (ref. 16 and G. I. Welsh, unpublished observations). Because GSK-3 is itself inactivated in response to insulin ${ }^{16,17}$, this provides a pathway for the activation of initiator TRNA binding, which is essential for the translation of all mRNAs and should lead to an across-theboard stimulation of translation. Together these mechanisms could therefore bring about both the general activation of initiation and selective increases in the expression of particular mRNAs.

Christopher G. Proud is in the Department of Biochemistry, School of Medical Sciences, University of Bristol, University Walk, Bristol BS8 1TD, UK.

1. Redpath, N. T. \& Proud, C. G. Biochim. biophys. Acta 1220. 147-162 (1994).

2. Pause, A. Belsham, G. J., Gingras, A.-C., Donzé, O., Lin, T.-A., Lawrence, J. C. Jr \& Sonenberg, N. et al. Nature 371, 762-767 (1994)

3. Haystead, T. A. J., Haystead, C. M. M., Hu, C., Lin, T.-A. \& Lawrence, J.C. Jr J. biol. Chem. 269, 23185-23191 (1994).

4. Lin, T.-A., Kong, X., Haystead, T. A. J., Pause, A Belsham, G., Sonenberg, N. \& Lawrence, J. C. Jr Science 266. 635-656 (1994)

5. Morris, D. R., Kakegawa, T., Kaspar, R. L. \&White, M.W Biochemistry 32, 2931-2937 (1993).

6. Sonenberg, N. Gene Expression 3, 317-323 (1993). 7. Hu, C., Pang, S., Kong, X., Velleca, M. \& Lawrence, J.C. Proc. natn. Acad Sci. U.S.A. 91, 3730-3734 (1994).

8. Belsham, G. J. \& Denton, R. M. Biochem. Soc. Trans. 8 , 382-383 (1980).

9. Blackshear, P. J.. Nemenoff, R. A.\& Avruch, J Biochem J. 214, 11-19(1982)

10. Diggle, T. A. \& Denton, R. M. Biochem. J. 282, 729-736 (1992)

11. Diggle, T. A., Bloomberg, G. B. \& Denton, R. M. Biochem J. (in the press)

12. Manzella J M Rychlik W Rhoads R. E Hershey, J. W. \& Blackshear, P. J. J. biol. Chem. 266, 2383-2389 (1991)

13. Shantz, L. M. \& Pegg, A. E. CancerRes. 54, 2313-2316 (1994)

14. Ming, X. F. et al. Nature 371, 426-429 (1994)

15. Jefferies, H. B. J., Reinhard, G. Kozma, S. C. \& Thomas. G. Proc. natn. Acad. Sci. U.S.A. $91,4441-4445$ (1994).

16. Welsh, G. I. \& Proud, C. G. Biochem. J. 294.625-629 (1993).

17. Hughes. K., Ramakrishna, S., Benjamin, W. B. \& Woodgett, J. R. Biochem. J. 288, 309-314 (1992)

\section{Area of no return}

FRICTION is rather a subtle phenomenon. On the atomic scale, all surfaces are very rough. Two objects in contact touch only at a few high points, which carry all the load. The high local pressure deforms them against each other, and they coldweld together. The friction of sliding is the force needed to shear these microscopic welds.

Daedalus is now complicating this simple picture. He is creating surfaces slippery in one direction, but sticky in the other. Samples for electron microscopy are often 'shadowed' with metal. A beam of metal atoms, sprayed in vacuo from a low angle, paints each feature with a dramatic shadow of deposited metal on one side, like evening sunlight on a mountainous landscape. So Daedalus is shadowing engineering surfaces with solid lubricant molecules or weldweakening agents. They coat every microscopic peak on the surface, but on one side only. A surface so coated should show anisotropic friction.

Push it against another surface, and the two will weld together at their points of contact. But these microwelds will all be weakened on one side by the asymmetric deposits of coating agent. Slide the joint in one direction, and the weak sides will be put under tension: they will readily fail by crack propagation. Slide the joint the opposite way, and the tension will come on the strong sides of the welds. They will resist the push.

The best materials for the trials are copper and aluminium, whose surfaces normally seize together readily. Properly shadowed, however, they should be remarkably slippery in the 'easy' direction. When the technique has been perfected, Daedalus's one-way sliding surfaces will revolutionize the bolting and fastening industry.

One-way nuts will easily spin down their bolts, but will bind hard if turned the other way. So simple vibration will automatically ratchet them tight. Oneway nails, wedges and rivets will similarly glide smoothly into place, and will then grip with unyielding tenacity. Complete one-way self-assembling mechanisms may even be possible. Vibrate the system, and all the joints will slide along their rods, unfolding the whole structure firmly and irreversibly. Even the most violent buffeting or shaking will not imperil it, but will merely tighten its joints more firmly. Production engineers will be delighted; but scrap-merchants and repair-men, unable to dismantle the new products, will grind their teeth in frustration. Daedalus's one-way components will be even more unremovable than those infuriating crosshead screws. David Jones 